\title{
Confianza y cooperación. Una perspectiva evolutiva*
}

\section{Trust and cooperation. An evolutionary perspective.}

\author{
CRISTINA ACEDO \\ ANTONI GOMILA \\ Grupo Cognición y Evolución Humana \\ Unidad asociada al IFISC (CSIC-UIB) (España)
}

Recibido: 27-1-2013

Aprobado definitivamente: 05-2-2013

\section{RESUMEN}

En esta contribución pretendemos reivindicar la necesidad de tener en cuenta las relaciones de confianza a la hora de tratar de entender la evolución de la cooperación. En este artículo, tras motivar el interés de tener en cuenta el papel de la confianza en la evolución de la cooperación, revisamos el concepto de confianza, como una actitud compleja que presupone vinculación afectiva y expectativas normativas, y proponemos una tipología que permite ordenar su variedad. Sostenemos que la complejidad de la cooperación humana tiene que ver con la manera en que los homínidos desarrollaron el andamiaje psicológico que hizo posible la confianza, y tratamos de proponer un escenario de su origen.

PALABRAS CLAVE

\section{CONFIANZA, COOPERACIÓN, EVOLUCIÓN SOCIAL}

\section{ABSTRACT}

In this paper we contend that trust has to be taken into account to explain the evolution of human cooperation. After showing that current models within evolutionary game theory overlook the role of trust, we offer our understanding of this concept, as a complex attitude that involves affective filiations and normative expectations, and put forward a typology of kinds of trust.

* Este trabajo ha recibido el apoyo del Ministerio de Economía y Competitividad, a través del proyecto FFI2010-20759. CA ha recibido el apoyo del Ministerio de Educación, a través de la beca FPU AP2009-2423 
We argue that the complexity of human cooperation was made possible in the psychological scaffolding that characterizes hominid evolution and made trust relationships possible. We also advance an hypothesis about the origin of trust.

KEYWORDS

TRUST, COOPERATION, SOCIAL EVOLUTION

\section{INTRODUCCIÓN}

Desde Darwin, la conducta social humana se ha visto como un reto particularmente difícil para la teoría evolutiva, ya que supone una aparente contradicción con el principio básico de la evolución, que prosperan los organismos con mayor aptitud biológica, es decir, que están en mejor disposición para reproducirse (Cela-Conde 1985). El alto nivel de cooperación que caracteriza las sociedades humanas, e incluso la posibilidad de conductas altruistas -esto es, conductas que suponen un coste para quien las realiza, para beneficiar a otro-, parece requerir una renuncia a la aptitud propia para beneficiar a la ajena. La solución a esta paradoja pasa por poder mostrar que, a largo plazo, esta estrategia de cooperar acaba siendo más beneficiosa para quien coopera. Pero también exige la identificación de los mecanismos que permiten asegurar tal tipo de conducta cooperativa.

Un primer intento de resolver ambas cuestiones consiste en el denominado «altruismo de parentesco», y la noción relacionada de «aptitud inclusiva» (Hamilton 1964). Según esta teoría, las conductas altruistas y cooperativas pueden explicarse si los beneficiarios son parientes; es más, la teoría permite predecir el nivel de cooperación y la disposición al sacrificio propio en beneficio de otro individuo, en función del grado de parentesco (Dawkins 1976; Axelrod y Hamilton 1981). La idea de fondo es que la aptitud biológica no debe verse únicamente a nivel de cada organismo individual, sino a nivel de los genes que los organismos comparten. Esta teoría, que ofrece una elegante explicación del altruismo en el seno de las sociedades de insectos (Wilson 1975), resulta más complicada de extender a especies cuya vida social no garantiza la proximidad genética de sus miembros, o donde no es fácil establecer cuál es el grado efectivo de parentesco. En otras palabras, la explicación evolutiva de la conducta social no puede quedarse en el nivel de los efectos de las conductas (a quién beneficia), sino que debe tener en cuenta también los mecanismos que median tales conductas, y aspirar a dar cuenta también de su evolución.

En el caso humano, en particular, es evidente que tales mecanismos son psicológicos (Rosas 2008). Comprender la cooperación humana, por tanto, no puede limitarse a explicar cómo puede darse el altruismo biológico - conductas que benefician a otro y suponen un coste a la aptitud biológica de quien las 
realiza-, sino también deben tener en cuenta los mecanismos psicológicos de los que depende la realización de tales conductas: en el caso humano, lo que podríamos llamar la disposición a ayudar, a tener en cuenta los intereses de los demás, o incluso a contar con normas morales que nos exigen actuar en beneficio ajeno -el altruismo moral (Cela-Conde 1990). Una explicación satisfactoria de la evolución social humana debe dar razón de ambos aspectos, el conductual y el psicológico.

Un avance en tal sentido se encuentra ya en la teoría del altruismo recíproco de Trivers (Trivers 1971). Cuando el comportamiento altruista humano se extiende más allá de los parientes puede ser impulsado por relaciones de reciprocidad, que se analizan en realidad como una forma de mutualismo asincrónico. De este modo, una conducta altruista forma parte de un esquema de cooperación que se despliega en el tiempo: quien recibe el favor, lo devuelve más tarde. Ambos participantes en la relación acaban obteniendo una aptitud biológica superior que la que podrían obtener sin tal intercambio. Según el propio Trivers, para que estas relaciones de reciprocidad puedan emerger son necesarios ciertos mecanismos psicológicos: de reconocimiento de la individualidad de los demás, de memoria del «balance» de la relación (quién está en deuda con quién), de detección de tramposos, además de amplias oportunidades para la colaboración. Según la simulación de Axelrod (1984), la evolución de la reciprocidad directa depende de la difusión en la población de una estrategia «tit-for-tat» -que podría traducirse «ojo por ojo» 0 «tal para cual»-, que depende a su vez de la capacidad de imitar la estrategia ajena, lo que supone además un mayor control de la conducta así como flexibilidad cognitiva.

En la reciprocidad indirecta, sin embargo, la ayuda a un sujeto no implica una compensación directa por parte de la misma persona ayudada, sino por parte de otra persona indirectamente relacionada, generando así una cadena de interacciones cooperativas. Un enfoque que da sentido a la reciprocidad indirecta ha sido la «selección de grupo», que postula que puede darse un proceso selectivo entre grupos competidores, en el que los miembros de los grupos que desarrollen pautas de cooperación general gozarán de mayor aptitud biológica en consecuencia (Boyd y Richerson 1990; Wilson y Sober 1994; Bergstrom 2002). De nuevo, las condiciones que hacen viable esta posibilidad son muy restrictivas, como por ejemplo, que los grupos sean cerrados, que no haya intercambios, lo cual no parece haber sido el caso a lo largo del Paleolítico.

Del mismo modo, la hipótesis del «altruismo fuerte» (Boyd y colaboradores 2003; Fehr y Gachter 2002) tampoco resulta convincente en relación a la evolución de la socialidad humana. Esta teoría propone una visión más sofisticada de la evolución de la cooperación, al introducir un nuevo mecanismo psicológico. Esta propuesta sostiene que la cooperación emerge gracias a la existencia de individuos dispuestos al castigo altruista, es decir, dispuestos a incurrir un 
coste personal para penalizar la conducta no cooperativa de otro en relación a un tercero. Esta disposición se ha relacionado con la existencia de expectativas normativas en el seno del grupo, que constituirían el germen de un sentido de justicia (Gintis 2003), aunque esta dimensión normativa va más allá de las capacidades psicológicas requeridas para el castigo altruista: simplemente, la disposición a penalizar a los tramposos, más allá de ser capaz de detectarlos, como proponía la teoría del altruismo recíproco. La dimensión normativa, asî como la importancia de las emociones morales en su mediación, representan, en nuestra opinión, un nivel de complejidad aun mayor.

Sin embargo, este modelo, a pesar de su éxito actual, se enfrenta a críticas. A nivel de modelo teórico, se enfrenta a la posibilidad que los aprovechados de segundo orden: individuos que se benefician de la disposición general al castigo altruista: dejan en manos de los demás castigar a quienes evitan cooperar, con lo que se ahorran el coste del castigo (Guala 2012). Pero, más importante, a nivel empírico, es escasa la evidencia sobre la existencia real de las personas que practican el altruismo fuerte. Las simulaciones que avalan la hipótesis de que la cooperación podría emerger por esta vía requieren de grupos homogéneos con rasgos distintos, que son difícilmente trasladables a contextos sociales reales. Y los experimentos de laboratorio, que han recurrido al juego del ultimátum, han mostrado que las ofertas que no alcanzan cierto nivel de equidad (al menos una distribución 70/30) son rechazadas (Camerer 2003), y que la posibilidad de castigar al tramposo efectivamente incrementa los niveles de cooperación (Fehr y Gachter 2002), pero únicamente entre los participantes en el juego, no en el caso contrario (Fehr y Fischbacher 2004). Finalmente, la evidencia etnográfica no proporciona muchos ejemplos de este tipo de castigo a nivel de prácticas colectivas (Marlowe et al. 2008). Los escasos ejemplos identificados sugieren más bien que el «castigo altruista», cuando aparece, no implica un gran esfuerzo a nivel individual.

La idea, por tanto, de que la cooperación social resulta de que todo el mundo está vigilante y dispuesto a castigar a quien no coopera, no resulta muy plausible. En las sociedades humanas surgen más bien instituciones especializadas en el castigo como modo de asegurar sus bienes comunes (Ostrom 1990). Ahora bien, quien sí está dispuesto a «castigar» de algún modo a quien no coopera es el perjudicado por la falta de reciprocidad, pero el castigo en tal caso consiste más bien en evitar la relación en el futuro. Esta relación, en realidad, tiene más sentido desde la perspectiva de la confianza: puede verse más bien como un caso de confianza defraudada, que tiene un efecto claro y bien conocido en la disposición a seguir cooperando con el responsable de la brecha en la confianza. Pero esta apreciación sugiere que la confianza supone un elemento mediador útil en la explicación de la cooperación humana. Y al mismo tiempo, sugiere la necesidad de explicar cómo pudieron emerger estas relaciones de confianza 
de las que parece depender efectivamente la vida social. Además, la confianza ofrece una prometedora vía para integrar conceptos psicológicos, sociológicos y antropológicos en un enfoque evolutivo.

Así pues, desde nuestro punto de vista, la cooperación y el altruismo en la interacción cooperativa humana están mediados por relaciones de confianza variables entre los agentes. Esto, a su vez, implica un análisis en el que los sujetos están inmersos inevitablemente en un contexto lleno de matices relacionados con un entorno cultural y normativo de la sociedad a la que pertenece el individuo en el que las estructuras y las dinámicas de confianza están inmersas, pero que mantienen la huella del contexto en el que las relaciones de confianza surgieron y se desarrollaron durante la mayor parte del proceso evolutivo. En este trabajo, nos proponemos avanzar en la clarificación de este concepto clave, que aparece en diversas disciplinas y teorías, distinguir sus diferentes variedades, así como plantear una hipótesis sobre la propia evolución de las relaciones de confianza, en su diversidad. Dejamos para un trabajo futuro el reto de desarrollar este enfoque con las herramientas de la modelización de la teoría evolutiva de juegos, para considerar su impacto en posibilitar los niveles de cooperación de las sociedades humanas.

\section{EL CONCEPTO DE CONFIANZA}

El concepto de confianza ha sido considerado desde muchos puntos de vista. Múltiples disciplinas, como la Psicología o las Ciencias Sociales han tratado de dar una definición basándose en sus propias visiones. Nos proponemos analizar la confianza desde una perspectiva antropológica y evolutiva, ya que proporciona los fundamentos para integrar diferentes aspectos de este concepto. Integrando las anteriores disciplinas se obtiene una comprensión más global de lo que es la confianza al distinguirse sus componentes emocionales, cognitivos, psicológicos y culturales.

La confianza parece responder a la necesidad de promover las relaciones sociales en contextos de riesgo en la creación de nuevas relaciones. El concepto de Parsons (1970) define literalmente la confianza como «[...] la actitud -de lealtad motivada afectivamente-para la aceptación de relaciones solidarias». Este concepto pone de relieve la idea de la importancia del componente emocional que sustituye a una inversión racional compleja en las relaciones sociales. Desde una perspectiva puramente racionalista sería muy difícil procesar toda la información relevante sobre las intenciones de los demás, para hacer juicios sobre su comportamiento y actuar en consecuencia. Lewis y Weigert (2001), por ejemplo, afirmaron que no es posible desarrollar planes de acción que tomen en cuenta todos los futuros contingentes posibles. Estos sesgos en favor de la economía cognitiva también fueron señalados por Yamagishi (2001). En consecuencia, desde el punto de vista del coste del procesamiento de la infor- 
mación relevante, la confianza podría haber emergido como una predisposición emocional basada en capacidades cognitivas limitadas donde las emociones y los mecanismos cognitivos están constantemente retroalimentándose, para promover acciones cooperativas conjuntas.

En el concepto de Parsons podemos encontrar algunos de los aspectos relevantes de la confianza. En primer lugar la palabra «actitud» se refiere a una tendencia a actuar de cierta manera. Esta tendencia podría ser apoyada por aspectos psicológicos y culturales, lo que refleja el entorno específico en donde surge y se desarrolla la confianza, así como los aspectos cognitivos implicados en la confianza. La palabra «afectivamente» se refiere al aspecto emocional antes mencionado. Por último, las «relaciones de solidaridad» se refieren al resultado de la confianza, es decir, a las relaciones de cooperación.

Las predisposiciones que Uslaner (2002) había llamado «los fundamentos morales de la confianza», implican un acto de fe positivo hacia los demás cuando no existe información sobre la que construir una acción, que requiere un contexto colectivo donde emerger y que proporciona un sentido de seguridad basado en la familiaridad. Pero en esta actitud están implícitos una variedad de elementos psicológicos, culturales, emocionales y cognitivos. Estos elementos pueden interactuar de varias maneras, resultando en diferentes tipos de confianza. A su vez, de estos diferentes tipos de confianza surgen diferentes tipos de relaciones cooperativas.

Es importante, por tanto, distinguir el concepto introducido hasta el momento, como una expectativa normativa sobre las intenciones de los demás en general, de la confianza que se genera a través de las expectativas de competencia (Barber 1983), que tienen un claro origen estrechamente relacionado con las capacidades de individuos concretos.

\section{A) ASPECTO EMOCIONAL}

El elemento emocional implícito en la confianza está muy relacionado con el origen y la dinámica de confianza. El aspecto emocional motiva como tal la acción para mantener o retirar la decisión de confiar en los demás.

Respecto al origen de la confianza, el aspecto emocional es pertinente porque la confianza surge como una manera de enfrentar el temor a los riesgos que implica la creación y mantenimiento de las relaciones sociales y cooperativas, al evitar el miedo a la incertidumbre y, por lo tanto, proporcionando una sensación de mayor seguridad. Existen de hecho relaciones de confianza con una gran cantidad de afecto implicado. Normalmente, el nivel de afectividad varía en función del nivel de confianza de las relaciones. En ocasiones, el nivel de afecto podría incluso ser en sí mismo una razón para la aparición de confianza sin tener en cuenta nada más, como en el caso de las relaciones amorosas, en 
las que de otro modo, sin mediar este sentimiento, la misma persona puede resultar poco confiable.

En relaciones estrechas muy afectivas, la traición produce altas dosis de dolor y resentimiento, mientras que en el caso de las relaciones de confianza más débiles, la traición provoca ira. Por otro lado, sentirse confiable promueve un sentimiento de satisfacción, a veces incluso de orgullo. Especialmente la sensación de ser digno de confianza -el sentimiento de aprobación por parte de otros- es un fuerte estímulo para mantener la confianza, lo que ayuda a mantener una personalidad confiable.

Las emociones que sustentan la confianza, por tanto, deben ser tenidas en cuenta entre las motivaciones que afectan a las acciones cooperativas.

\section{в) AsPecto cognitivo}

Los seres humanos necesitan ciertas habilidades cognitivas que hagan posible sus relaciones de confianza, lo cual hace de la confianza algo tan complejo en la especie humana, en comparación a otras especies.

La emergencia de la conciencia propia es un primer paso necesario en la confianza (Humphrey 1976; Crook 1980). Además, en el proceso de surgimiento de la confianza se genera una expectativa normativa sobre la actitud y la conducta de la persona confiada. Esta expectativa se basa primero en la atribución de un estado mental en el confiado (teoría de la mente), y en la expectativa de un patrón de comportamiento obligado, basado en un análisis realizado dentro de un contexto. Esta expectativa también implica el manejo de información relevante por parte del confiador acerca del confiado para tomar la decisión de confiar en él, lo cual constituye un análisis de múltiples variables sobre las que inferir una conclusión -un proceso de razonamiento para hacer un juicio adecuado de la situación. La información recopilada en este proceso depende asimismo de cómo el confiador percibe e interpreta la realidad. La forma de percibir lo que nos rodea es también parte del proceso cognitivo implícito en la confianza (Good, 1988).

El complejo proceso cognitivo incluye además el uso de esquemas y estereotipos -como las categorías sociales-, así como las atribuciones interpersonales -como son los roles-que influyen en la forma de atribuir ciertas características en otros y que a veces intervienen en la confianza. Ocasionalmente, la confianza requiere una visión sobre las intenciones de otros a largo o medio plazo, lo cual puede implicar una planificación futura y también ciertas capacidades de memoria compleja que permita la recogida y tratamiento de toda esta información. Todas estas tareas son cognitivas y hacen de la cooperación humana una conducta más consciente y compleja que la de otras especies y que depende de todas estas variables que intervienen en el procesamiento cognitivo. Es por ello por lo que la variabilidad de las respuestas cooperativas se diversifica y 
se complica a la hora de intentar predecirla ya que depende de muchos más factores en la especie humana.

\section{C) ASPECTOS PSICOLÓGICO Y CULTURAL}

El aspecto psicológico de la confianza hace referencia a los rasgos psicológicos adquiridos por el individuo durante los primeros años de vida, ya sea por su origen genético, la influencia familiar, o por el contexto social en el que se desarrolla el sujeto, que tienen influencia en su tendencia general a la hora de confiar en otros. Este aspecto puede conectarse con una actitud del individuo hacia los demás, a veces hacia los extraños.

Muchos estudios han intentado identificar actitudes psicológicas relacionadas con la confianza. Rotter (1980) descubrió que los individuos más confiados generalmente son también los más confiables y los más queridos por sus amigos; también son menos propensos a mentir, engañar o robar, a ser infelices o inadaptados. Del mismo modo, Uslaner (2002) afirma que la autoevaluación positiva es uno de los predictores más fuertes de la confianza, y Freitag y Traunmüller (2009) piensan que la predisposición general a confiar está muy cercana a rasgos psicológicos como la actitud optimista. En este sentido, Wrightsman (1966) concluye que las personas altruistas, honestas e independientes confían más en los demás que las personas con actitudes hostiles hacia la naturaleza humana. Por otra parte, ser una persona de confianza implica según Hardin (2006) una fuerte motivación psicológica para mantener esta actitud de aprobación.

El aspecto cultural, por su parte, se refiere a todas aquellas construcciones intangibles creadas por una sociedad que son reconocidas, compartidas e interiorizadas por sus miembros, y que influyen en su organización colectiva y en la acción individual. Esto incluye las normas compartidas, creencias, costumbres, prácticas, hábitos, valores, experiencias, etc... Es importante tener en cuenta que esta dimensión cultural es un factor que puede afectar también a la confianza puesto que el marco de creencias, normas y valores compartidos por un grupo social puede modular las interacciones de confianza dentro de ese grupo de una forma característica. Así, por ejemplo, Yamagishi (1998) apela a diferencias en las formas culturales de confianza entre los habitantes de Japón y Estados Unidos, como explicación de los patrones diferentes de cooperación en el seno de cada sociedad.

Dentro de este aspecto cultural están incluidos además los sistemas de educación que intervienen en el desarrollo de los individuos; las reglas establecidas formalmente por las instituciones gubernamentales para crear un ambiente colectivo de mayor o menor confianza y seguridad; así como las reglas implícitas culturalmente transmitidas entre los miembros de una sociedad que se internalizan como un conjunto de conductas de confianza, que se comparten y son reconocidos por todos los individuos de una comunidad, y que se basan 
en valores transmitidos por generaciones y consolidados por medio de hábitos y rutinas diarias de sus prácticas culturales. Las creencias religiosas también forman parte de esta dimensión cultural que pueden favorecer o limitar ciertas conductas de confianza y predisponer el conjunto adecuado de destinatarios legítimos. Así mismo, determinados acontecimientos históricos pueden influir considerablemente en la consolidación de algunas actitudes de confianza en los individuos de una población y también pertenecen a esta categoría. Así pues, a la hora de analizar cómo surgen y funcionan las actitudes cooperativas en los individuos y en los grupos, habría de hacer referencia a esta multiplicidad de variables que modulan las posibilidades de actos cooperativos.

\section{TIPOS DE CONFIANZA}

El interés en el análisis de confianza proviene de los estudios sobre el capital social (Coleman 1990; Fukuyama 1995; Glaeser y colaboradores 1999; Uslaner 2002). La clasificación de confianza más extendida considera dos tipos: la denominada confianza particularizada y confianza generalizada (Uslaner 2002; Yamagishi y Yamagishi 1994). Los orígenes de ambos tipos de confianza parecen ser diferentes. El primero aparece como un producto de las experiencias individuales más o menos positivas de confianza del sujeto, mientras que el segundo parece basarse en predisposiciones innatas o aprendidas mediante mecanismos psicológicos en edades tempranas del individuo.

La confianza particularizada, denominada por Yamagishi (1998) «confianza basada en el conocimiento» y «confianza fuerte» por Putnam (2000), se refiere a la confianza creada por los vínculos más estrechos, normalmente familiares, amigos y conocidos. Este tipo parece surgir en un contexto de familiaridad de interacciones reiteradas donde la experiencia de las prácticas cotidianas puede mantener o romper el grado de confianza entre las personas.

La confianza generalizada, «confianza general» (Yamagishi 1998), o «confianza débil» (Putnam 2000), se refiere más bien al «sentido moral de confianza» de Uslaner, que se utiliza en relaciones más débiles y distantes, incluso con extraños, y depende de ciertas predisposiciones naturales, basadas en actos de fe hacia la buena conducta de los demás. Según Uslaner (1999), este tipo de confianza sería más estable y más difícil de cambiar por las experiencias diarias, una afirmación que es polémica.

Muchos autores han intentado explicar los factores que tienen más influencia en la confianza generalizada. Por ejemplo, Glanville y Paxton (2007) sugieren que la confianza generalizada está más influida por el contexto que por factores psicológicos; en particular, subrayan la notable influencia de los vecinos y personas con quien el individuo interactúa en tiendas. Otros estudios (Delhey y Newton 2010; Bjørnskov 2006) también corroboran la influencia de factores comunitarios en la confianza generalizada. Delhey y Newton (2010) concluyen 
que los elementos que pueden influir en la difusión de la confianza generalizada varían dependiendo de las circunstancias específicas de cada país. Según Bjørnskov (2006), los países con monarquía parecen mostrar mayores niveles de confianza generalizada, y los países post-comunistas muestran mayores niveles de desconfianza. Estos mismos trabajos, que utilizan una perspectiva sociológica que parten de un análisis estadístico que utilizan regresiones y ciertos indicadores sociales para explicar la generación de confianza, pueden resultar confusos porque tales indicadores utilizados para medir la confianza pueden ser más bien un reflejo de su consecuencia que un factor explicativo. Además las categorías elegidas como variables explicativas podrían estar implícitamente interconectadas, en cuyo caso no proporcionan un claro argumento para explicar la creación de confianza.

Desde un punto de vista evolutivo, sería más comprensible la integración de experiencias colectivas y predisposiciones individuales, admitiendo su interrelación y constante retroalimentación, para crear un espectro de formas de confianza, que se vinculará a contextos particulares. Dentro de estas formas de confianza, se podrían distinguir diferentes esferas que pueden contribuir a una tipología de confianza más sofisticada. Esta tipología distingue diferentes etapas en la formación de la confianza, tanto a lo largo del desarrollo individual en un contexto determinado como a lo largo del proceso evolutivo:

1. La «confianza generalizada»: correspondiente a la confianza influenciada por elementos innatos y aprendidos en entornos de relaciones estrechas en edades tempranas y que originan una actitud general de confianza hacia los demás, que podría ser afectada por otras experiencias en la vida del individuo.

2. La «confianza personalizada»: correspondiente a la confianza particularizada basada en experiencias reiteradas con individuos concretos que forja el círculo de relaciones cercanas.

3. La «confianza institucional»: influenciada por organismos institucionales, que establecen políticas para crear un marco de normas y valores como mecanismos de socialización, que pueden afectar a la confianza en los miembros de la sociedad. Autores como Luhmann (1979) estudiaron esta influencia.

4. La «confianza identitaria»: que crea una tendencia a confiar en las personas con quienes se comparten características comunes, formando grupos de confianza. Desde este punto de vista, Foddy, Platow y Yamagishi (2009) afirman que «la confianza basada en el grupo» actúa en presencia del reconocimiento mutuo de pertenencia a un grupo compartido, rasgos de identidad, reconocimiento de las características 
más favorables a los miembros del grupo y la expectativa del comportamiento altruista y justo por parte de ellos.

5. La «confianza contextual»: adquirida a través de características del sujeto puramente contextuales que se refieren a rasgos tales como la edad de los individuos, sexo, lugar de residencia, origen, educación, nivel de ingresos, etc..., circunstancias que podrían influir en el grado de confianza individual.

6. La «confianza ponderada»: se refiere al asunto sobre el que se confía. El confiador puede confiar en el confiado en relación con un asunto, pero no igualmente en relación con otro porque el nivel de riesgo implicado en cada asunto puede valorarse de forma diferente según el individuo del que se trate.

7. La «confianza estratégica»: se refiere a la confianza surgida del interés propio en confiar en otro, que puede ser mutua o no, para obtener un objetivo. Incluso si no se basa en un sentido real de confianza, se corre el riesgo porque podría considerarse necesario para alcanzar una meta. A veces este tipo de confianza se apoya en el conocimiento de que la persona en la que se confía responderá según las expectativas depositadas porque también está interesada en la relación de confianza-«interés encapsulado» de Hardin (2002). Además, este tipo de confianza crea el entorno necesario para la aparición del capital social -inversión en relaciones sociales beneficiosas para el individuo-, aumentando las posibilidades de una respuesta positiva del confiado. En consecuencia, este tipo de confianza, más que basarse en sentimientos reales de confianza, se basaría en una intención consciente de su uso para obtener capital social.

Estas esferas de confianza parecen no estar aisladas, sino interconectadas e influirse mutuamente para moldear, no sólo una personalidad confiada, sino también una personalidad confiable.

En cuanto a la interacción entre las esferas de confianza, un ejemplo lo constituye la confianza generalizada. La confianza generalizada puede ser influida en primera instancia por la confianza personalizada puesto que determinadas relaciones muy estrechas dejaron su huella en las interacciones sociales durante los primeros años de vida. También puede estar influida por la confianza institucional, ya que los valores difundidos por organismos institucionales pueden transmitirse también en esos primeros años, o por una confianza identitaria que puede ser inculcada también a través de las conductas de las personas que rodean al individuo durante los primeros años de vida. Así mismo, la confianza generalizada puede alimentarse de forma positiva según autores como Freitag y Traunmüller (2009), que afirman que la confianza es influida por experiencias 
positivas con extraños pero no por experiencias negativas. La confianza generalizada incluso podría ser influenciada por la confianza contextual, estratégica o ponderada.

Otro ejemplo de interacción respecto de la confianza ponderada podría ser la obra de Jones y George (1998), que distinguen entre confianza condicional e incondicional. La diferencia se refiere respectivamente a las actitudes de confianza que no implican un coste significativo para el confiador respecto de aquellas actitudes de confianza que podrían requerir un perjuicio propio. Este estudio parece pertinente porque a veces los niveles de confianza difieren no sólo respecto al objeto de confianza sino también debido a las actitudes y los valores promovidos en ciertos contextos que contribuyen a crear relaciones con una mayor o menor implicación personal. Este caso podría ser un ejemplo de las influencias institucionales en la confianza ponderada.

En la tendencia a cooperar nos encontramos pues con la posibilidad de la existencia de estas diferentes influencias a la hora de impulsar la confianza entre los individuos que interactúan, a veces para realizar acciones solidarias, otras para desmotivar las acciones comunes debido a influencias negativas que provengan de las fuentes mencionadas.

\section{DiNÁMICAS DE CONFIANZA Y COOPERACIÓN}

\section{A) CREACIÓN Y MANTENIMIENTO}

Las necesidades humanas más primarias -afectividad, ayuda, apoyo, compañía y seguridad-impulsan hacia la cooperación y requieren la existencia de confianza.

Entre las motivaciones afectivas a confiar, están las que provienen de la familia o relaciones de amigos, personas enamoradas (Yamagishi 1998), o la confianza que proviene de extraños con rasgos amigables. Los «rasgos amistosos», incluyen ciertos rasgos faciales, gestos y actitudes que contribuyen a crear un sentido de confianza entre extraños (Scharlemann y colaboradores 2001; Tingley 2010).

Pero la confianza no siempre viene acompañada de un sentimiento afectivo. Pueden existir otras razones para la aparición de confianza separadas del contexto afectivo, como hemos visto anteriormente. Este sería el caso de la «confianza estratégica» para la búsqueda de objetivos diferentes -lo que Hardin (2002) llama «interés encapsulado» y Yamagishi (1998), «garantía de seguridad».

Entre las motivaciones para la confianza estratégica están la creación y mantenimiento de la reputación (Coleman 1990; Cook y Hardin 2001), la búsqueda de intereses mutuos o metas compartidas (Conviser 1973), el establecimiento y expansión de las redes sociales, la obtención de ayuda para hacer frente a los cambios, etc.... En este caso se podría hablar de una cierta cooperación «interesa- 
da» que busca una reciprocidad directa o indirecta. La confianza además puede apoyarse meramente en influencias morales del contexto en el que el confiador se mueve y no en sus expectativas originales; también puede ser influida por ciertos compromisos (Hardin 2006). En estos casos, la confianza no supone una sensación real de expectativa positiva respecto al sujeto de confianza.

El mantenimiento de la confianza depende del tipo de confianza, de este modo, la confianza particularizada necesita de una constante demostración de confianza a través de las experiencias cotidianas para construirse, paso a paso y persona a persona. En un contexto de intimidad estrecha entre sujetos, donde las emociones son más intensas, la confianza puede ser más vulnerable. En consecuencia, se requiere de la repetición de acciones y experiencias positivas, para reforzar y mantener la actitud confiadora. En la confianza generalizada, por el contrario, mantener una actitud positiva hacia los demás parece ser una cualidad más estable, aunque algunos autores consideran que podrían ser necesarias las experiencias positivas para mantener esta actitud positiva. Otras influencias externas que influyen en la creación y mantenimiento de la confianza son, como ya se ha mencionado, el entorno cultural, institucional y contextual del individuo.

\section{B) OBSTÁCULOS PARA CONFIAR Y COOPERAR}

La confianza es a menudo difícil de crear y mantener debido a múltiples factores. Entre ellos merece especial atención el grado de asimetría implícito en la confianza (Hardin 2002; Six 2005), porque sólo necesita unas pocas experiencias negativas para perderse y un conjunto de experiencias positivas reiteradas para mantenerse, lo cual constituye un obstáculo para su fácil expansión. La confianza se basa además en percepciones y predicciones sobre el comportamiento del otro (Six 2005), lo que supone una débil base para la creación y mantenimiento de la confianza, que la hace muy vulnerable a factores puramente especulativos y a veces altamente maleables por las decisiones políticas, por los medios de comunicación, los entornos educativos, etc...

Decidir confiar implica un riesgo, requiere mucha apertura a los demás y a veces exponerse a actos de otras personas que pueden producir una carga emocional muy intensa en el confiador. Confiar en que alguien no garantiza la certeza de que esa persona responderá a las expectativas. Todos estos elementos pueden causar reticencias en los individuos a tomar esos riesgos. Con respecto a la resolución de posibles conflictos de confianza, la falta de una comprensión clara de lo que es la confianza y de cómo funciona, así como los múltiples factores que le pueden afectar, pueden hacer difícil su resolución. 


\section{EvOLUCIÓN DE LA CONFIANZA}

Una vez identificados los diferentes aspectos que afectan a la modelización de la confianza, resulta más fácil recrear el ambiente en el que esta característica pudo surgir y evolucionar.

En términos evolutivos, parece razonable pensar el origen de la confianza en las relaciones más cercanas del entorno familiar. Se trata de relaciones personales, creadas a través de fuertes vínculos de emociones básicas intensas, a lo largo del largo período de maduración humana, cuando el individuo se encuentra en una situación de dependencia de sus progenitores. En este período, toman forma ciertas actitudes, así como las expectativas acerca de otros sobre la base de la experiencia - confianza personalizada. Este tipo de relaciones familiares, que son compartidas por muchas otras especies y que fundamentan la base de sus actitudes confiadoras y cooperativas, en el linaje homínido se transforman debido a las nuevas dimensiones cognitivas y culturales adquiridas en dicha especie. Por tanto, las acciones cooperativas pasan de un entorno puramente familiar en muchas especies al entorno grupal, lo cual crea una ventaja adaptativa.

Así, en entornos sociales más complejos, como el de los humanos, en donde las relaciones de confianza se extienden no sólo a los miembros de parentesco, tales conductas sociales, que requieren de capacidades cognitivas más complejas, resulta en la aparición de grupos con individuos dominantes, coaliciones y jerarquías. Otras especies cooperan en grupos más o menos grandes sobre la base de mecanismos no cognitivos, a veces exclusivamente basados en la bioquímica. Sin embargo, en el caso de muchos primates y en el caso humano, en particular, estos nuevos tipos de relaciones fuera del ámbito del parentesco, implican un mayor riesgo social y en consecuencia la necesidad de realizar un seguimiento del comportamiento de los demás para seleccionar contactos más estrechos con algunos individuos que con otros. Para tener éxito en las luchas de poder, dominación o simplemente supervivencia, la capacidad cognitiva para generar confianza pudo desarrollarse como una estrategia beneficiosa que posibilita nuevas relaciones cooperativas. La confianza recrea una sensación de familiaridad que proporciona seguridad en contextos inseguros y esta familiaridad pudo ser usada para motivar la acción cooperativa o competitiva respecto a los sujetos que no forman parte del círculo de confianza, en contextos sociales más complejos.

Los primates utilizan el aseo mutuo como medio de vinculación (Dunbar 1998), para crear relaciones más estrechas entre los miembros del grupo que ayuden a obtener ciertos objetivos -en analogía con el capital social. Estas relaciones de intercambio y reciprocidad parecen señales muy primitivas de acciones para promover la confianza, que ayudan a crear esa sensación de fa- 
miliaridad que la confianza requiere. Este es un ejemplo de cómo cooperación y confianza se refuerzan mutuamente.

En el caso humano, la confianza ha adoptado características muy complejas, coherentes con las mayores posibilidades de procesamiento cognitivo humano, que se diversifican en formas diversas de confianza. La supervivencia en entornos difíciles, donde la supervivencia no puede conseguirse de modo individual, sino que depende de la cooperación social, hacen de la capacidad para establecer vínculos de confianza algo biológicamente valioso. Tras revisar las evidencias que muestran que la confianza puede ayudar a crear y mejorar los vínculos cooperativos, Yamagishi (1998) concluye: «ante una alta incertidumbre social y altos costes de oportunidad, los muy confiadores tendrán mayor oportunidad de conseguir más beneficios que los que confían menos» (pp. 56). En consecuencia, los individuos que crean vínculos más fuertes y más diversificados tienen más posibilidades de sobrevivir que aquellos que limitan la confianza a pocas personas porque diversifican las posibilidades de obtener cooperación. Esta necesidad de vincularse a otros con fines comunes pudo constituir la presión evolutiva que animó la tendencia a confiar como medio para reducir la ansiedad causada por la necesidad de tomar grandes riesgos, a veces al dejar la propia vida en manos de otros. Este nuevo escenario de socialización en grupos pequeños durante la mayor parte de la evolución humana pudo ser el entorno de aparición de otros tipos de confianza, por ejemplo, la confianza estratégica o la confianza identitaria.

Según Uslaner (2002), la creación de un entorno basado en la confianza puede fomentar la cohesión y una mayor tendencia a ayudar a los demás, la solidaridad y la unión en el seno del grupo. En los primeros días de la evolución humana, en los que los grupos humanos eran pequeños y donde inicialmente pudieron no haber existido grandes diferencias de poder entre los individuos, una organización social más o menos igualitaria pudo haber fomentado la confianza y la cooperación, beneficiando a todos sus miembros.

A medida que los grupos humanos se hicieron más numerosos, sin embargo, las relaciones de confianza tuvieron que cambiar y adaptarse a relaciones sociales en contextos más complejos y diversos. Sin embargo, confianza personal con los individuos más cercanos se mantuvo en relaciones con una mayor carga emocional, pero haciéndose posible también una tipología más flexible de formas de confianza, para promover acciones en común con individuos menos conocidos. Siendo demasiado costoso cognitivamente mantener un fuerte vínculo con un número ilimitado de individuos, lo cual requiere invertir mucho tiempo y comprometerse a establecer encuentros frecuentes (Dunbar 2003), así como el tratamiento de gran cantidad de información, se desarrolló una tendencia general a confiar, de mayor flexibilidad, basada en los recursos culturales en los que los seres humanos se habían especializado. 
De esta manera, en sociedades más complejas a nivel cultural y organizativo, la confianza pudo evolucionar en formas de confianza generalizada, institucional, contextual y ponderada, utilizando en este proceso una gama de emociones más complejas también. Así, por ejemplo, la confianza generalizada pudo haber surgido apoyándose menos en la experiencia interpersonal, la cual era imposible de extender a todos los individuos conocidos, para basarse más en una actitud aprendida hacia los demás. En estos tipos de confianza, el componente emocional pierde intensidad en afectividad, pero hace posible ampliar el número de interacciones y contactos de capital social. La evolución de la cooperación implica la evolución de la confianza en una tipología con más matices y gradaciones.

\section{REFERENCIAS BIBLIOGRÁFICAS}

AXELROD, R. y HAMILTON W. D. 1981: «The evolution of cooperation», Science, vol. 211, pp. 1390-1396.

AXELROD, R. 1984: The evolution of cooperation. New York: Penguin.

BARBER, B. 1983: The logic and limits of trust. New Brunswick, New Jersey: Rutgers University Press.

BERGSTROM, T. C. 2002: «Evolution of social behaviour: Individual and group selection», Journal of Economic Perspectives, vol. 16, pp. 67-88.

BJØRNSKOV, C. 2006: «Determinants of generalized trust: a cross-country comparison», Public Choice, vol. 130, pp. 1-21.

BOYD, R., GINTIS, H., BOWLES, S. y RICHERSON, P. 2003: «The evolution of altruistic punishment», Proceedings of the National Academy of Sciences, vol. 100, pp. 3531-3535.

BOYD, R. y RICHERSON, P. 1990: «Group selection among alternative evolutionarily stable strategies», Journal of Theoretical Biology, vol. 145, pp. 331-342.

CAMERER, C.F. 2003: Behavioral Game Theory. Princeton University Press.

CELA-CONDE, C.J. 1985: De genes, dioses y tiranos: sobre la determinación biológica de la moral. Alianza Editorial.

, 1990: «On the phylogeny of human morality (ten years later)». Human Evolution, vol. 5, no 2, pp. 139-151.

COLEMAN, J. 1990: Foundations of social theory. Cambridge: Belknap Press.

CONVISER, R. H. 1973: «Toward a theory of interpersonal trust», The Pacific Sociological Review, vol. 16, no. 3, pp. 377-399.

COOK, K. S. y HARDIN, R. 2001: «Norms of cooperativeness and networks of trust», en M. Hechter y K.D. Opp (eds), Social norms. New York: Russell Sage, pp. 327-347. 
CROOK, J. H. 1980: The evolution of human consciousness. Oxford: Oxford University Press.

DAWKINS, R. 1976: The selfish gene. New York: Oxford University Press.

DELHEY, J. y NEWTON, K. 2010: «Who trusts? The origins of social trust in seven societies», European Societies, vol. 5, no. 2, pp. 93-137.

DUNBAR, R. 1998: «The social brain hypothesis», Evolutionary Anthropology, vol. 6, pp. 178-190.

, 2003: «Social network size in humans», Human Nature, vol. 14, no.1, pp. $53-72$.

FEHR, E. y GACHTER, S. 2002: «Altruistic punishment in humans», Nature, vol. 415, pp. 137-140.

FEHR, E. y FISCHBACHER, U. 2004: «Third-party punishment and social norms». Evolution and Human Behavior, vol. 25, pp. 63-87.

FODDY, M., PLATOW, M. J. y YAMAGISHI, T. 2009: «Group-based trust in strangers», Psychological Science, vol. 20, no. 4, pp. 419-422.

FREITAG, M. y TRAUNMÜLLER, R. 2009: «Spheres of trust: An empirical analysis of the foundations of particularised and generalised trust», European Journal of Political Research, vol. 48, pp. 782-803.

FUKUYAMA, F. 1995: Trust: the social virtues and creation of prosperity. New York: Free Press.

GINTIS, H. 2003: «The hitchhiker's guide to altruism: Gene-culture coevolution, and the internalization of norms». Journal of Theorectical Biology, vol. 220, nº 4, pp. 407-418.

GLAESER, E. L., LAIBSON, D., SCHEINKMAN, J. A. Y SOUTTER, C. L. 1999: What is social capital? The determinants of trust and trustworthiness. Cambridge: National Bureau of Economic Research.

GLANVILLE, J. L. y PATXON, P. 2007: «How do we learn to trust? A confirmatory tetrad analysis of the sources of generalized trust», Social Psychology Quarterly, vol. 70, no. 3, pp. 230-242.

GOOD, D. 1988: «Individuals, interpersonal relations, and trust», en D. G. Gambetta (ed.), Trust. New York: Basil Blackwell, pp. 131-185.

GUALA, F. 2012: «Reciprocity: Weak or strong? What punishment experiments do (and do not) demonstrate», Behavioral and Brain Sciences, vol. 35, pp. 1-59.

HAMILTON, W. D. 1964: «The Genetical Evolution of Social Behaviour I and II», J. Theor. Biol. v7, pp 1-16, and 17-52

HARDIN, R. 2002: Trust and trustworthiness. New York: Russell Sage Foundation. , 2006: Trust. Cambridge: Potity Press.

HUMPHREY, N. 1976: «The social function of intellect», en P. P. G. Bateson y R. A. Hinde (eds.), Growing points in ethology. Cambridge: Cambridge University Press, pp. 303-317.

JONES, G. R. y GEORGE, J. M. 1998: «The experience and evolution of trust: implications for cooperation and teamwork», Academy of Management Review, vol. 23 , no. 3, pp. 531-546. 
LEWIS, J. D. y WEIGERT, A. 2001: «Trust as a social reality», Social Forces, vol. 63, no. 4, pp. 967-985.

LUHMANN, N. 1979: Trust and power. London: John Wiley and Sons.

MARLOWE, F.W., BERBESQUE, J.C., BARR, A., BARRETT, C., BOLYNATZ, A., CARDENAS, J.C., ENSMINGER, J., GURVEN, M., GWAKO, E., HENRICH, J., HENRICH, N., LESOROGOL, C., MCELREATH, L., y TRACER, D. 2008: «More 'altruistic' punishment in larger societies». Proceedings of the Royal Society $B$ vol 275, pp. 587-592.

OSTROM, E. 1990: Governing the Commons: The evolution of institutions for collective action. Cambridge University Press.

PARSONS, T. 1970: «Research with human subjects and the «professional complex», en P. Freund (ed.), Experimentation with human subjects. New York: Braziller, pp. 116-151.

PUTNAM, R. D. 2000: Bowling alone: the collapse and revival of american community. New York: Simon y Schuster.

ROSAS, A. 2008: «The return of reciprocity: a psychological approach to the evolution of cooperation». Biology and Philosophy, vol. 24, pp. 555-566.

ROTTER, J. B. 1980: «Interpersonal trust, trustworthiness, and gullibility», American Psychologist, vol. 35, no. 1, pp. 1-7.

SCHARLEMANN, J. P., ECKEL, C. C., KACELNIK, A. y WILSON, R. K. 2001: «The value of a smile: Game theory with a human face», Journal of Economic Psychology, vol. 22, pp. 617-640.

SIX, F. 2005: The trouble with trust. The dynamics of interpersonal trust building. Massachusetts: Edward Elgar Publishing Limited. 